\title{
EV Charging in a Commercial Hybrid AC/DC Microgrid: Configuration, Control and Impact Analysis
}

\author{
Md Shamiur Rahman, Student Member, IEEE, M. J. Hossain, Senior Member, IEEE, \\ F. H. M. Rafi, Student Member, IEEE, and Junwei Lu, Senior Member, IEEE
}

\begin{abstract}
The progressive deployment of electric vehicles (EVs) and the increased penetration of direct current (DC) and alternating current $(\mathrm{AC})$ type renewable resources pave the path towards hybrid AC/DC microgrid operations. Considering the potential future participation of EVs in a hybrid AC/DC microgrid environment, this paper presents a generalized synopsis on $\mathrm{EV}$ charging in a commercial hybrid AC/DC microgrid. Constituents of this paper encompass the charger configurations, vehicle-togrid (V2G) control strategies of individual chargers and their effects on the microgrid operations. Impacts of three types of EV chargers are considered in this paper which include three-phase $\mathrm{AC}$ and DC fast charging and single-phase residential charging. All configurations and their control strategies are developed in MATLAB/SIMULINK environment. Initial simulations are carried out considering real commercial load and solar irradiation data which shows stable microgird operations. Later the impacts of various types of $\mathrm{EV}$ charging on the $\mathrm{AC}$ and $\mathrm{DC}$ bus voltages and frequency of the commercial hybrid AC/DC microgrid are analyzed. The obtained results highlight the implications of bulk coordinated EV charging to reduce adverse operational impacts and network investment.
\end{abstract}

Index Terms-Hybrid AC/DC microgrid, Fast charging, Interlinking converter, Vehicle-to-grid (V2G), Energy storage systems, Photovoltaics (PV) units

\section{INTRODUCTION}

$\mathbf{R}$ ESIDENTIAL and commercial buildings of the modern world are consuming nearly $32 \%$ of the total energy generation. These buildings are inadvertently responsible for about $30 \%$ of the $\mathrm{CO}_{2}$ emissions related to the total end-ofuse energy consumption [1]. Utilization of renewable resources with progressively deployed EVs can be used as a feasible way of reducing $\mathrm{CO}_{2}$ emission. This way can guarantee energy security and reliable load balancing [2]. However, effects of EV charging in a low voltage (LV) network or in a microgrid need to be considered before massive deployment of EVs. Moreover, additional investments are required to increase the capacities in all sectors of generation, transmission, and distribution to meet the growing charging demands of EVs. Photovoltaic (PV) units are renewable sources which can produce energy anywhere as long as there is sunlight, including commercial and residential areas for EV charging. Therefore, the collective combination of PV units with EV charging stations is a likely way to efficiently revamp increasing charging

Md Shamiur Rahman, M. J. Hossain, F. H. M. Rafi and Junwei $\mathrm{Lu}$ are with Griffith School of Engineering, Griffith University, Gold Coast, QLD - 4222, Australia (e-mail: mdshamiur.rahman@griffithuni.edu.au, j.hossain@griffith.edu.au, fida.rafi@griffithuni.edu.au, j.lu@griffith.edu.au).
TABLE I: Different EV charging profiles [8]

\begin{tabular}{lllll}
\hline \multicolumn{1}{c}{$\begin{array}{c}\text { Charging } \\
\text { time }\end{array}$} & Type & Power & Voltage & $\begin{array}{c}\text { Max. } \\
\text { current }\end{array}$ \\
\hline 6 8 hours & Single-phase & $3.3 \mathrm{~kW}$ & $230 \mathrm{~V}$ & $16 \mathrm{~A}$ \\
$3 \sim 4$ hours & Single-phase & $7.4 \mathrm{~kW}$ & $230 \mathrm{~V}$ & $32 \mathrm{~A}$ \\
2 3 hours & Three-phase & $10 \mathrm{~kW}$ & $400 \mathrm{~V}$ & $16 \mathrm{~A}$ \\
$1 \sim 2$ hours & Three-phase & $22 \mathrm{~kW}$ & $400 \mathrm{~V}$ & $32 \mathrm{~A}$ \\
20 30 minutes & Three-phase & $43 \mathrm{~kW}$ & $400 \mathrm{~V}$ & $63 \mathrm{~A}$ \\
20 30 minutes & Direct current & $50 \mathrm{~kW}$ & $400 \sim 500 \mathrm{~V}$ & $100 \sim 125 \mathrm{~A}$ \\
10 minutes & Direct current & $120 \mathrm{~kW}$ & $300 \sim 500 \mathrm{~V}$ & $300 \sim 350 \mathrm{~A}$ \\
\hline
\end{tabular}

demand during daytime, and lessen the dependency on the existing power grid [3].

Usual working hours for the commercial building can be segmented into two portions that include the morning portion which usually spans from 9:00 AM to 1:00 PM and the afternoon portion which spans from 2:00 PM and afterwards. Most EVs arrived at the parking lot/charging stations can be charged during these two portions. EV charging demands can be met by PV units with or without the battery energy storage systems (BESS) that support PV units. Improved load profile with reduced peak demand can be achieved and other negative impacts on the distribution grid owing to EV charging can be reduced by properly allocating PV power for EV charging [3]. Recent literatures in references [4]-[7] have studied different charging strategies for LV distribution system and for the commercial building microgrid with EVs and PV units. However, till now no literature consider the impacts of EV charging in a commercial microgrid with hybrid AC/DC configuration.

A hybrid AC/ DC microgrid is suggested and explored in some contemporary literatures [9]-[11] to incorporate the benefits of both $\mathrm{AC}$ and DC types of the electricity infrastructures. A hybrid AC/DC microgrid offers multiple advantages over conventional $\mathrm{AC}$ and $\mathrm{DC}$ microgrids. This structure requires less $\mathrm{AC} / \mathrm{DC}$ conversion which is viable to integrate $\mathrm{DG}$ units and loads of both AC and DC types. Individual AC and DC buses requires less efforts in synchronization. Moreover, it provides simple voltage transformation capability, which can be achieved by transformers in the $\mathrm{AC}$ side and by DC/DC converters in the DC side. Therefore, the overall efficiency are increased added with reliable and economical operation [12].

Apart from the hybrid configuration of the commercial microgrid, different charger configurations such as DC fast chargers and three-phase AC chargers (slow and fast) and 


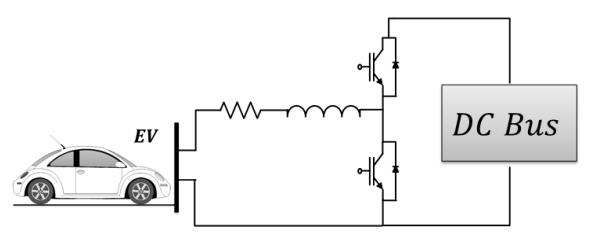

(a) DC fast charger

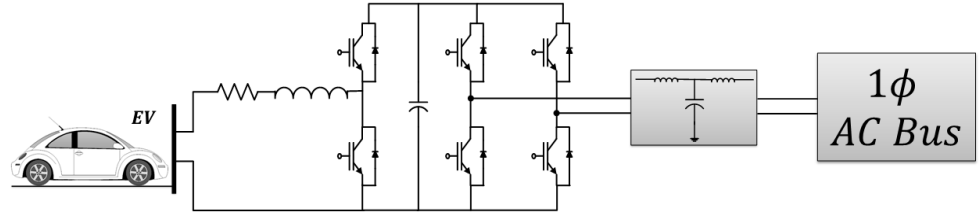

(b) Single-phase AC domestic charger

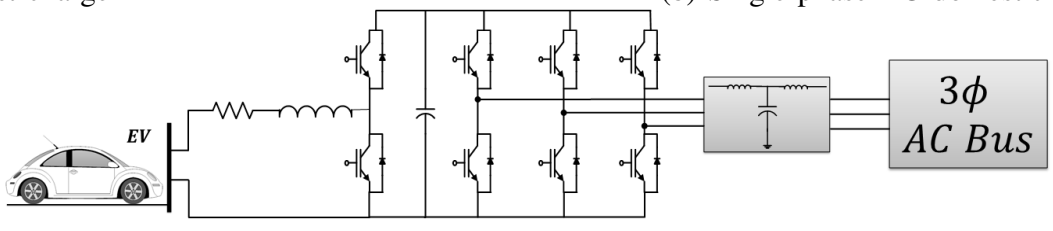

(c) Three-phase AC fast charger

Fig. 1: Typical configurations of various EV chargers

single-phase AC chargers make the EV charging a problematic task [13]-[14]. For instance, phase voltages and currents in a LV distribution network or microgrid can exceed the acceptable range of unbalanced condition if the penetration level of single-phase or residential EV charging is higher than the rated capacity of the network [15]. Moreover, each charging configurations have their own sets of standards which can be further classified as slow and fast charging. Different types of EV chargers and their corresponding charging time, maximum power consumption, maximum current drawing capability and standard voltage levels are given in Table I.

Based on the above mentioned scopes and trends, this paper investigates the impact of various types of $\mathrm{EV}$ charging in a commercial hybrid AC/DC microgrid. Initially an overview on different configurations of EV chargers and their control strategies are briefly discussed. Three types of charging strategies have been considered in the paper i.e. DC fast charging, three-phase $\mathrm{AC}$ fast charging and single-phase AC residential/domestic charging. Each charging configurations and their control strategies have been developed and implemented in MATLAB/SIMULINK environment. The commercial hybrid AC/DC microgrid is developed resembling Griffith University microgrid model. Since a hybrid AC/DC microgrid requires both $\mathrm{AC}$ and $\mathrm{DC}$ bus voltages along with the frequency to be regulated simultaneously, impact of various types of EV charging on $\mathrm{AC}$ and $\mathrm{DC}$ bus voltages and the frequency are observed and compared with the normal operating condition. The salient contributions of this paper are:

- Providing a generalized overview on the charging configurations and individual control strategies of various types of EV chargers which include DC, three-phase AC and single-phase AC chargers,

- Analysing the impacts of aforementioned chargers on voltage and frequency profile of the hybrid AC/DC microgrid and comparing the results with normal operating condition of the microgrid

The rest of the paper presents four sections. Section II introduces the test commercial hybrid microgrid in Griffith University, Australia and its simulated version. This section also includes a brief description of various charging configurations and their control strategies. Case studies to investigate the impacts of EV charging and their comparative analysis are provided in Section III. Later on concluding remarks for the paper are provided in Section IV.

\section{SyStem CONFIGURATION}

The hybrid AC/DC microgrid system are composed of three buildings of the Griffith University, Australia viz. N44, N05 and N74 as illustrated in Fig. 5 of Appendix A. All buildings are going to be constructed as hybrid AC/DC microgrids that can operate in both islanded and grid-tied mode. There are individual $\mathrm{AC}$ and $\mathrm{DC}$ buses for each of the three buildings. These buses accommodates alike type loads and sources. N44 building contains PV panel with energy storages systems which are linked via DC/DC converters to the designated DC bus. N05 is solely planned for bidirectional EV/PHEV charging which enables V2G operation. N74 comprises of sensitive loads connected to both AC and DC buses. This building is presently served by backup diesel generator and battery energy storage during grid power outage [13], [16].

The simulation model of this paper is designed containing islanded N44 and N05 microgrid building. N44 building is modelled using a $250 \mathrm{~kW}$ PV unit with $60 \mathrm{kWh}$ high capacity BESS. PV units include PV panels and corresponding boost converters with maximum power point tracking (MPPT) system. Energy storage systems are connected via DC/DC converter controlled by an energy management algorithm. N05 building is designed with an EV-ESS and a DC/DC converter which are collectively linked to the DC bus along with threephase and single-phase EV-ESS connected to the AC bus. DC buses of N44 and N05 are linked with their corresponding AC buses via interlinking converters and LC filters. Commercial load data for one day from 9:00 AM to 5:00 PM (usual office hour) are used with real solar irradiation data for the same day for the PV unit.

An overview of the configurations and the control strategies used in this paper for DC type, three-phase AC and singlephase AC type EV chargers are briefly presented in subsequent sections.

\section{A. DC Fast Charger}

The configuration and the control strategy for the DC fast charger used in this paper are shown in Figs. 1a and 2a 


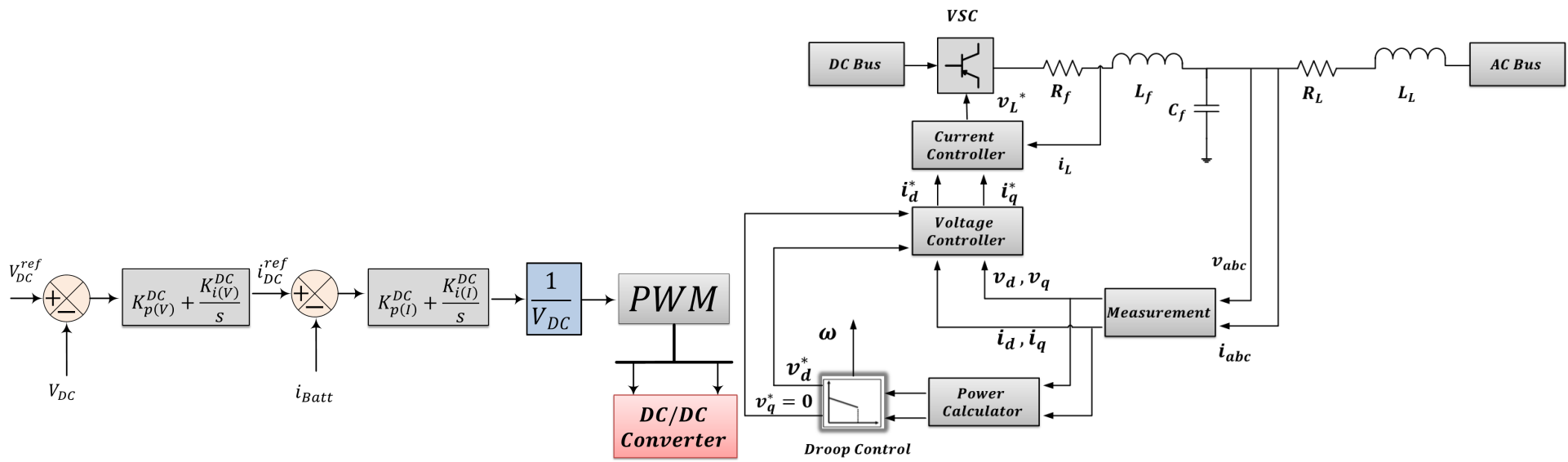

(a) DC fast charger

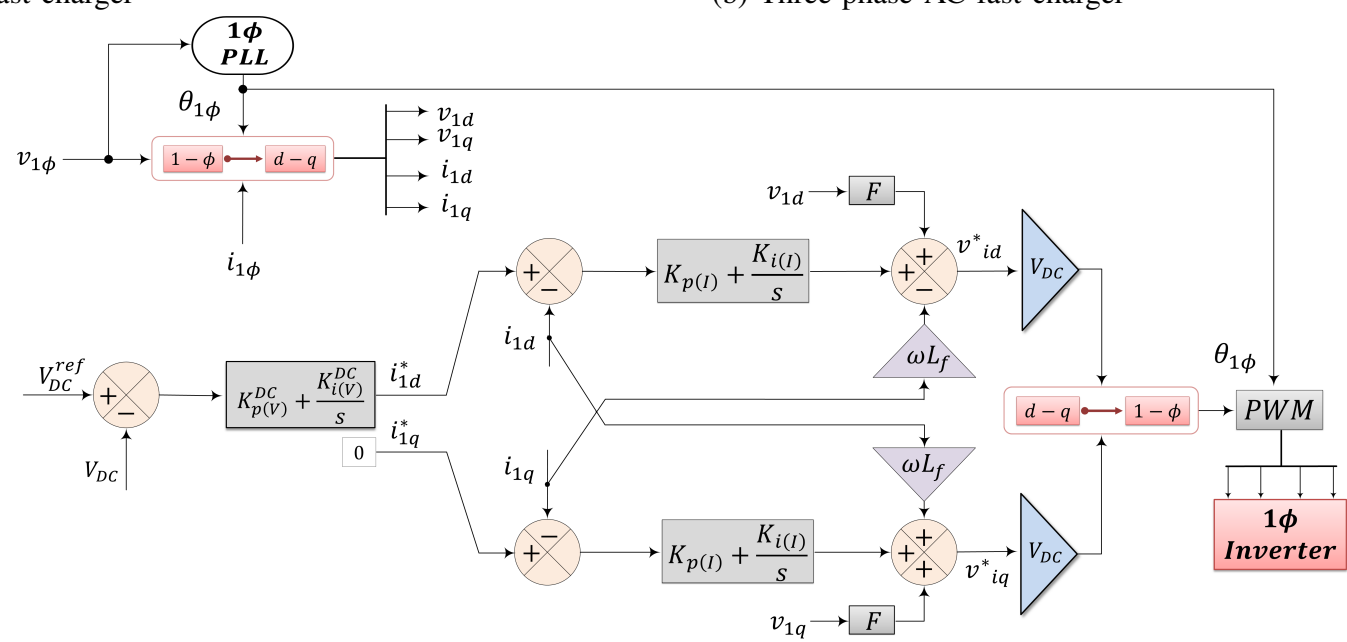

(c) Single-phase AC domestic charger

Fig. 2: Control strategies of various EV chargers

respectively. It includes a DC/DC converter as the interfacing converter for EV-ESSs. The control strategy for the DC/DC converter involves a voltage control loop (VCL) and a current control loop (CCL) as shown in Fig. 2a. The VCL stabilizes the DC link voltage of the voltage source inverter (VSI)/DC bus at $V_{D C}^{r e f}$. The VCL also generates reference current signals for the battery. The differential algebraic equations (DAEs) for the VCL and CCL of the controller are given as [17]:

$$
\left\{\begin{aligned}
i_{D C}^{r e f} & =\left(V_{D C}^{r e f}-V_{D C}\right)\left(K_{p(V)}^{D C}+\frac{K_{i(V)}^{D C}}{s}\right) \\
D_{B a t t} & =\frac{\left(i_{D C}^{r e f}-i_{B a t t}\right)\left(K_{p(I)}^{D C}+\frac{K_{i(I)}^{D C}}{s}\right)}{V_{D C}}
\end{aligned}\right.
$$

where $K_{p(V)}^{D C}$ and $K_{i(V)}^{D C}$ are the proportional and integral gains for the VCL respectively. $K_{p(I)}^{D C}$ and $K_{i(I)}^{D C}$ are the proportional and integral gains for the CCL respectively. The generated duty cycle for the pulse width modulation (PWM) of the converter is $D_{\text {Batt }}$.

\section{B. Three-phase AC Fast Charger}

Typical configuration of a bidirectional three-phase EV charger is shown in Fig. 1c. It consists of a DC/DC converter interfaced with a three-phase inverter. In practical cases, there is a galvanic isolation in between the converter and the inverter. The three-phase AC fast charger requires distinct control strategy to achieve V2G capability. The control strategy for the three-phase fast charger is illustrated in Fig. 2b. The control strategy is developed utilizing decoupled $d-q$ control of three-phase inverters using pulse-width modulation (PWM). It consists of three inner control loops i.e. power control loop (PCL), VCL and CCL. The PCL is basically a droop control that ensures effective bidirectional active and reactive power allocation among several EV units. The designed droop controller generates references for the voltage controller which are later fed to the current controller. Current controller generates necessary modulation signal for the inverter of the charger. Usually LCL filters are used after inverter in order to achieve smooth voltage and current wave shapes. Elaborate description of the control strategy for the three-phase AC fast charger used in this paper can be obtained from [13]. Though the primary focus of this paper is conventional charging, currently threephase AC faster charging system has been introduced under the umbrella of on-board charging system which utilises the internal bi-directional DC (Battery source) /AC (Motor drive) inverter. The AC Motor drive can be connected to a three- 
(a) DC bus voltage (V)

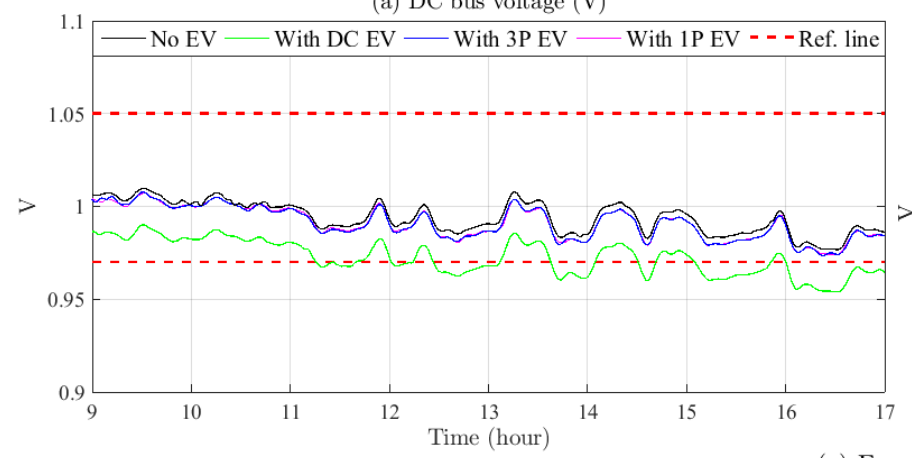

(c) Frequency $(\mathrm{Hz})$

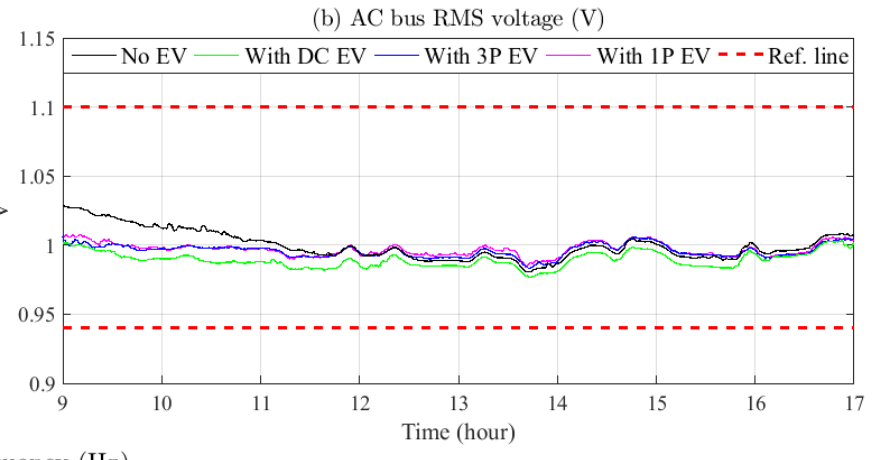

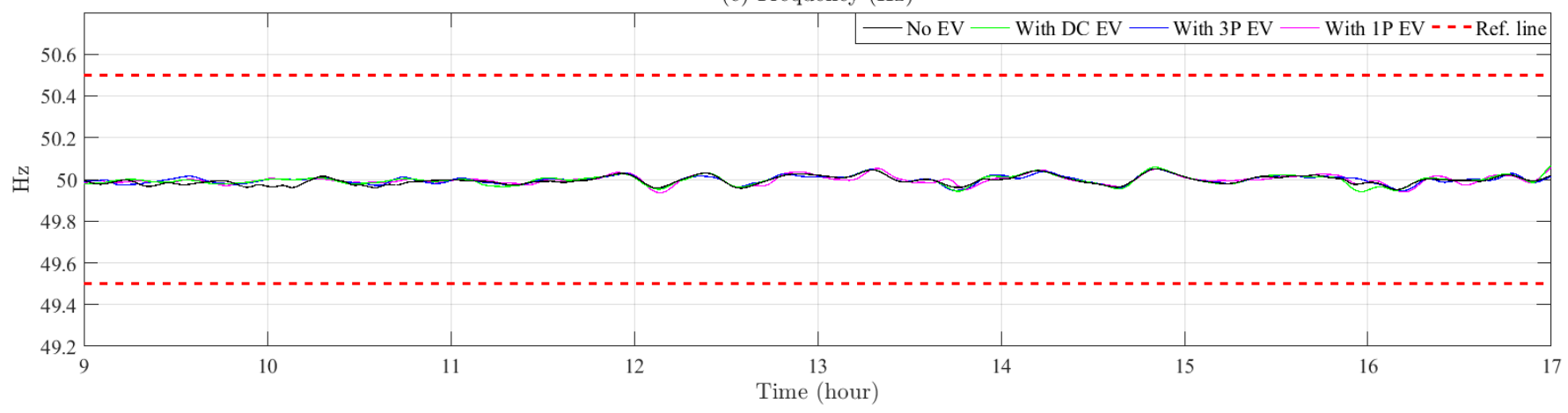

Fig. 3: Parameters of the hybrid AC/DC microgrid from 9:00 AM till 5:00 PM on a weekday: (a) DC bus voltage, (b) AC bus RMS voltage and (c) Frequency

phase AC side of $50 / 60 \mathrm{~Hz}$ only.

\section{Single-phase AC Domestic Charger}

Single-phase AC domestic charger configuration and control strategies are shown in Figs. $1 \mathrm{~b}$ and $2 \mathrm{c}$ respectively. Singlephase EV chargers are designed to operate as active loads. The operation of EVs is designed with single-phase phase-lockedloop (PLL) and associated controllers as proposed in [18]. Single-phase PLL includes one orthogonal signal generator which generates $\beta$ components of the single-phase input voltage and current signals. Later the virtual $\alpha-\beta$ components of the voltage and current are converted into $d-q$ components. The generated $d-q$ components are used in the decoupled $d-q$ synchronous reference frame (SRF) controller for single-phase inverters as presented in [19]. The terminal voltage magnitude of the single-phase AC chargers are reasonably constant due to their active load operating control strategy.

\section{CAse Studies}

Simulations are carried out to analyse and assess the impacts of above mentioned EV chargers in a commercial hybrid AC/DC microgrid environment. The test simulation includes a hybrid microgrid with a $250 \mathrm{~kW} \mathrm{PV}$ source and a $60 \mathrm{kWh}$ BESS at the DC subgrid and a $48 \mathrm{kWh}$ BESS at the AC subgrid. EV-ESSs of both DC and three-phase AC configurations are taken $48 \mathrm{kWh}$. The capacity for single-phase EVESSs are taken $19.2 \mathrm{kWh}$. The hybrid AC/DC microgrid and the control structures are developed in MATLAB/SIMULINK environment. The computational platform has following configurations: Intel(R) Core(TM) i5-4570 CPU $3.20 \mathrm{GHz}$ and 8.00 GB RAM. Three case studies are carried out i.e. DC fast charging operation, three-phase AC fast charging operation and single-phase AC slow charging/residential charging operation. Each case studies are compared with normal operating condition. Normal operating condition refers to the islanded microgrid operation with the commercial load profile and the real solar insolation data.

Initially the efficacy of the islanded microgrid operation is tested without considering any EV charging. The main purpose the test is to validate the efficiency of the interlinking converter during the period of islanded operation. Results of the normal operating condition are later used as a reference to analyse the impacts of different levels of EV charging. Integrated OSI PI software is used for data acquisition which collects data from the installed smart power meters of the building. The solar insolation data and the real and the reactive load of the N44 building are acquired for a particular weekday. In Fig. 3(ac), the AC and DC bus voltages and frequency of the system are presented in black colour. The acceptable ranges for DC and $\mathrm{AC}$ bus voltages are taken as specified in [20] and [21] whereas the frequency range is taken as given in [22].

\section{A. DC fast charging operation}

In this case study DC fast charging is considered from 9:00 AM to 5:00 PM. It is considered that the EVs are connected directly to the DC bus of the micrgrid through DC fast charger. Here DC EV chargers are consuming constant $62.5 \mathrm{~kW}$ of real power. Results obtained from the simulation is presented in Figs. 3 and 4. It can be observed from the Fig. 3 that introduction of DC fast charger severely affects the DC bus voltage, However, the frequency and the AC bus RMS voltage of the AC subgrid are not severely affected. 
(a) Average $\% \mathrm{SOC}$ of different EV chargers

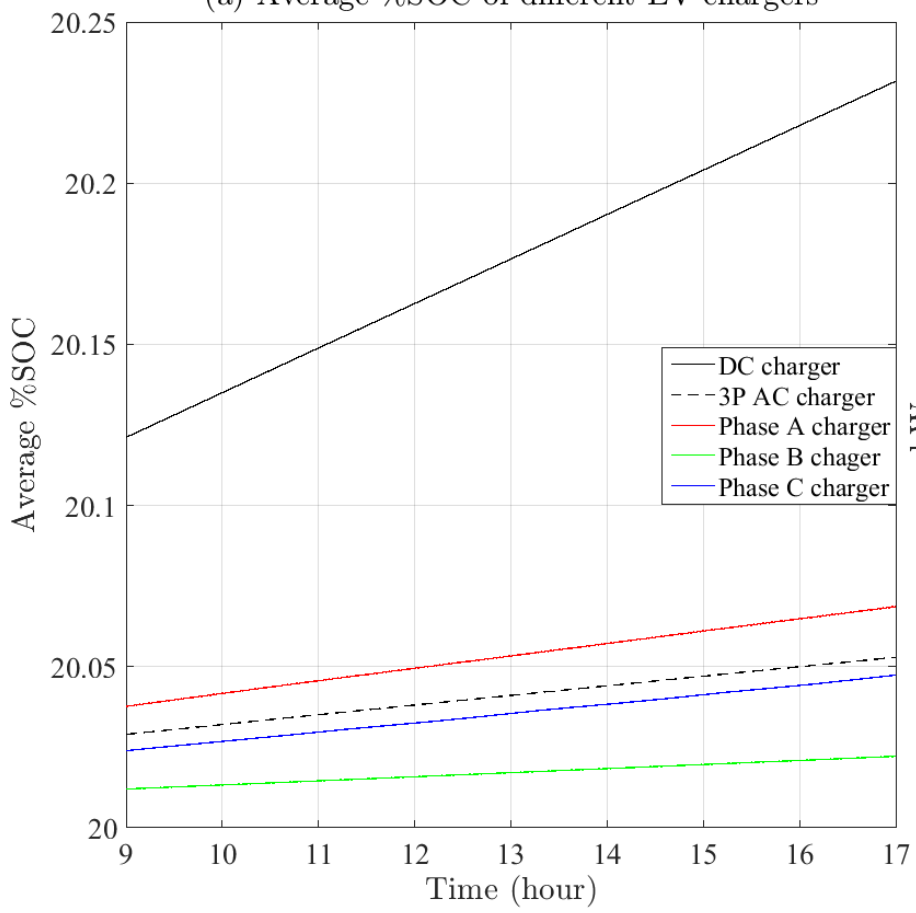

(b) Average power drawn by different EV chargers $(\mathrm{kW})$

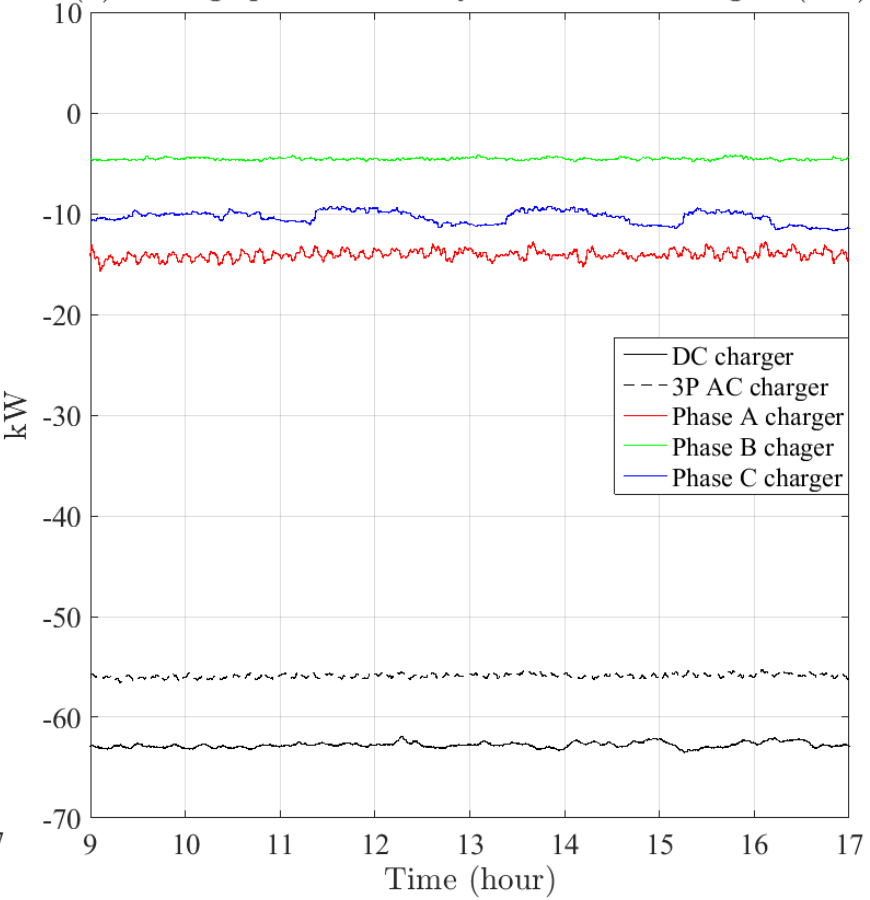

Fig. 4: EV chargers' profile: (a) Average \%SOC of different types of EV chargers and (b) Average power drawn by different EV chargers

It is because of the high active power consumption of the EV chargers which causes mismatch between generated and consumed active power which results in lower DC bus voltage. A tendency of slight reduction in AC bus RMS voltage can be observed in Fig. 3(c) for the same reason. Therefore, it can be assumed that with the increased number of DC EV chargers the AC bus RMS voltage will be affected as well. The frequency is not severely affected due to the robust nature of the droop controller in the interlinking converter. The average $\%$ state of charge (SOC) for the DC charger presented in Fig. 4(a) demonstrate steep rise due to fast charging. Real power drawn by the charger is presented in Fig. 4(b).

\section{B. Three-phase AC charging operation}

This case study is done by charging the EV in a three-phase distribution feeder. EV is connected directly to the three-phase line through three-phase charger. The charging duration and the conditions are kept similar to the previous case study. Results for this case study is presented in Fig. 3 and 4 for comparison purposes. It can be observed that the three-phase $\mathrm{AC}$ charging has limited impacts on the system voltages and frequency. This is due to the robust nature of the designed droop controller. Even though the three-phase AC charging does not have severe effects on microgrid performances as compared to the DC fast charging, increased number of EV charging can deviate the voltage and frequency profile noticeably.

\section{Single-phase AC charging operation}

In this case study each phase of the three-phase system is loaded differently. The average drawn power by individual single-phase EV chargers are shown in Fig. 4(b). For this case study, phase A, B and C are considered to be loaded with 5, 10 and 2 numbers of single-phase EV chargers, each consuming approximately $5.5 \mathrm{~kW}$. The effects on the magnitude of the voltages and frequency is minimal due to the active load operational model of the single-phase EV chargers.

\section{CONCLUSION}

In this paper, a generalized synopsis is presented for different types of electric vehicle charging systems which include DC fast charging, three-phase AC charging and single-phase AC charging. An overview of the control strategies of these chargers is also discussed. Primarily simulations are carried out to show that without bulk EV charging the developed controllers can ensure stable microgrid operation. However, adverse effects on DC bus voltage and minimal negative effect on AC bus RMS voltage are observed with increased number of EV charging. The obtained results highlight the importance of coordinated charging strategies to reduce the adverse effects of bulk EV charging on emerging microgrid environment and possible network investment.

\section{APPENDIX A \\ HYbRID AC/DC MICROGRID IN GRIFFITH UNIVERSITY}

See Fig. 5.

\section{REFERENCES}

[1] J. V. Roy, N. Leemput, F. Geth, R. Salenbien, J. Büscher, and J. Driesen, "Apartment building electricity system impact of operational electric vehicle charging strategies," IEEE Transactions on Sustainable Energy, vol. 5, no. 1, pp. 264-272, Jan. 2014, ISSN: 1949-3029. 
[2] L. Jian, H. Xue, G. Xu, X. Zhu, D. Zhao, and Z. Y. Shao, "Regulated charging of plug-in hybrid electric vehicles for minimizing load variance in household smart microgrid," IEEE Transactions on Industrial Electronics, vol. 60, no. 8, pp. 3218-3226, Aug. 2013, ISSN: 02780046.

[3] N. Liu, Q. Chen, J. Liu, X. Lu, P. Li, J. Lei, and J. Zhang, "A heuristic operation strategy for commercial building microgrids containing evs and pv system," IEEE Transactions on Industrial Electronics, vol. 62, no. 4, pp. 2560-2570, Apr. 2015, ISSN: 0278-0046.

[4] J. V. Roy, N. Leemput, F. Geth, J. Büscher, R. Salenbien, and J. Driesen, "Electric vehicle charging in an office building microgrid with distributed energy resources," IEEE Transactions on Sustainable Energy, vol. 5, no. 4, pp. 1389-1396, Oct. 2014, ISSN: 1949-3029.

[5] P. J. Tulpule, V. Marano, S. Yurkovich, and G. Rizzoni, "Economic and environmental impacts of a pv powered workplace parking garage charging station," Applied Energy, vol. 108, no. C, pp. 323-332, 2013. [Online]. Available: http://EconPapers.repec.org/RePEc:eee:appene: v:108:y:2013:i:c:p:323-332.

[6] Y. M. Wi, J. U. Lee, and S. K. Joo, "Electric vehicle charging method for smart homes/buildings with a photovoltaic system," IEEE Transactions on Consumer Electronics, vol. 59, no. 2, pp. 323-328, May 2013, ISSN: 0098-3063.

[7] A. Mohamed, V. Salehi, T. Ma, and O. Mohammed, "Real-time energy management algorithm for plug-in hybrid electric vehicle charging parks involving sustainable energy," IEEE Transactions on Sustainable Energy, vol. 5, no. 2, pp. 577-586, Apr. 2014, ISSN: 1949-3029.

[8] Charging station. [Online]. Available: https://en.wikipedia.org/wiki/ Charging_station (visited on 06/16/2016).

[9] X. Liu, P. Wang, and P. C. Loh, "A hybrid ac/dc microgrid and its coordination control," IEEE Transactions on Smart Grid, vol. 2, no. 2, pp. 278-286, Jun. 2011, ISSN: 1949-3053.

[10] P. C. Loh, D. Li, Y. K. Chai, and F. Blaabjerg, "Autonomous control of interlinking converter with energy storage in hybrid ac/dc microgrid," IEEE Transactions on Industry Applications, vol. 49, no. 3, pp. 1374 1382, May 2013, ISSN: 0093-9994.

[11] J. M. Guerrero, P. C. Loh, T. L. Lee, and M. Chandorkar, "Advanced control architectures for intelligent microgrids part ii: power quality, energy storage, and ac/dc microgrids," IEEE Transactions on Industrial Electronics, vol. 60, no. 4, pp. 1263-1270, Apr. 2013, ISSN: 0278-0046.
[12] F. Nejabatkhah and Y. W. Li, "Overview of power management strategies of hybrid ac/dc microgrid," IEEE Transactions on Power Electronics, vol. 30, no. 12, pp. 7072-7089, Dec. 2015, ISSN: 08858993.

[13] M. S. Rahman, M. Hossain, and J. Lu, "Coordinated control of threephase ac and dc type ev-esss for efficient hybrid microgrid operations," Energy Conversion and Management, vol. 122, pp. 488-503, 2016, ISSN: 0196-8904.

[14] M. S. Rahman, F. Rafi, M. Hossain, and J. Lu, "Power control and monitoring of the smart grid with evs," Vehicle-to-Grid: Linking Electric Vehicles to the Smart Grid, p. 107, 2015.

[15] N. Leemput, F. Geth, J. V. Roy, A. Delnooz, J. Büscher, and J. Driesen, "Impact of electric vehicle on-board single-phase charging strategies on a flemish residential grid," IEEE Transactions on Smart Grid, vol. 5, no. 4, pp. 1815-1822, Jul. 2014, ISSN: 1949-3053.

[16] M. S. Rahman, M. J. Hossain, and J. Lu, "Utilization of Parked EV-ESS for Power Management in a Grid-Tied Hybrid AC/DC Microgrid," in The 25th Australasian Universities Power Engineering Conference 2015, 2015.

[17] A. A. A. Radwan and Y. A. R. I. Mohamed, "Networked control and power management of ac/dc hybrid microgrids," IEEE Systems Journal, vol. PP, no. 99, pp. 1-12, 2014, ISSN: 1932-8184.

[18] N. Bottrell, M. Prodanovic, and T. C. Green, "Dynamic stability of a microgrid with an active load," IEEE Transactions on Power Electronics, vol. 28, no. 11, pp. 5107-5119, Nov. 2013, ISSN: 08858993.

[19] S. Golestan, M. Monfared, J. M. Guerrero, and M. Joorabian, "A dq synchronous frame controller for single-phase inverters," in Power Electronics, Drive Systems and Technologies Conference (PEDSTC), 2011 2nd, Feb. 2011, pp. 317-323.

[20] B. Singh, P. Jayaprakash, T. R. Somayajulu, and D. P. Kothari, "Reduced rating vsc with a zig-zag transformer for current compensation in a three-phase four-wire distribution system," IEEE Transactions on Power Delivery, vol. 24, no. 1, pp. 249-259, Jan. 2009, ISSN: 0885-8977.

[21] T. A. P. Association, "Pv integration on australian distribution," no. September, 2013

[22] Parliament of the Commonwealth of Australia and E. Act, "Electricity Regulation 2006," Tech. Rep. 4, 2011. [Online]. Available: http:// www.legislation.qld.gov.au/legisltn/current/e/electricR06.pdf.

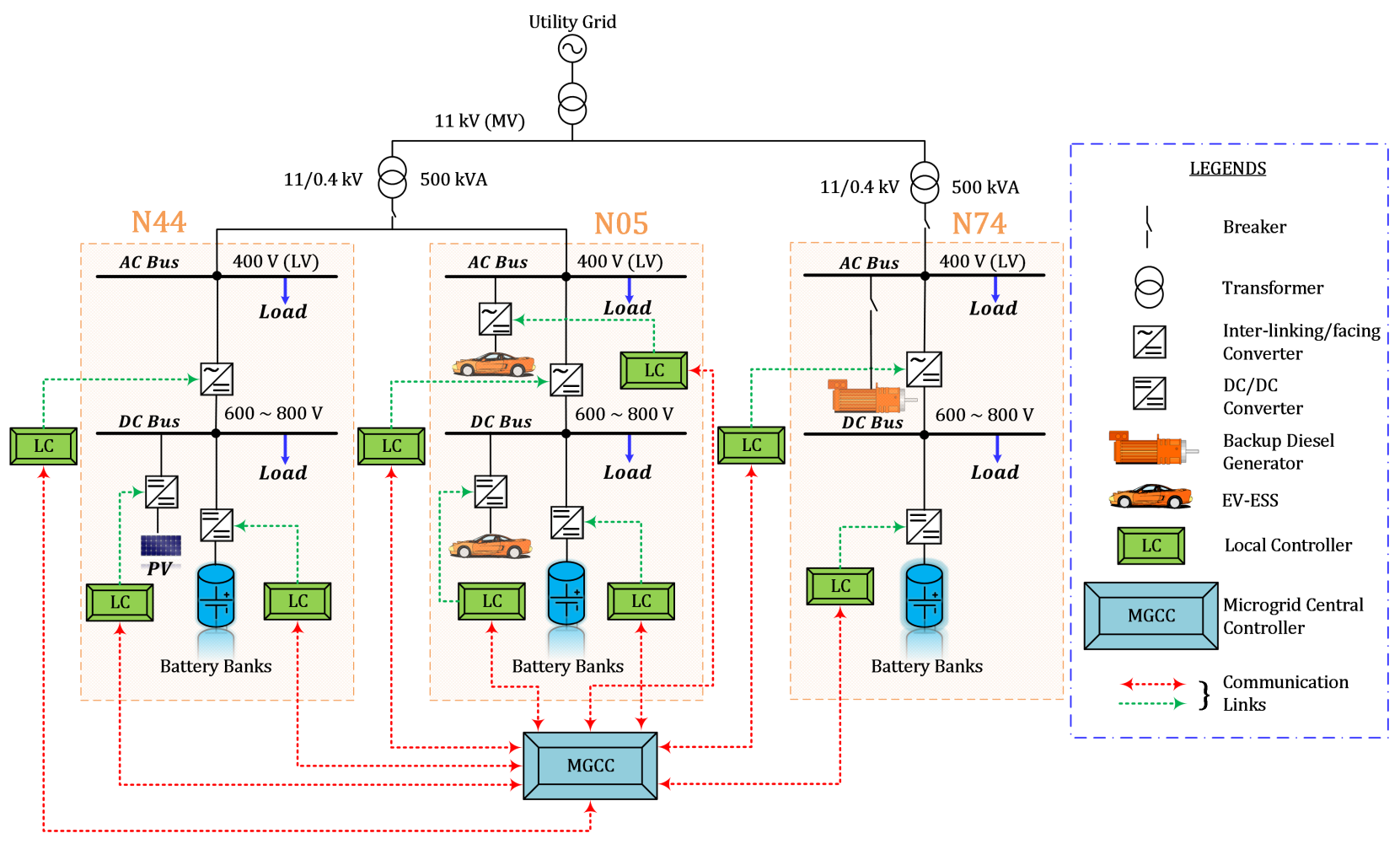

Fig. 5: Planned hybrid AC/DC microgrid structure in Griffith University, Australia 